\title{
Downregulation of miR-31 in Diabetic Nephropathy and its Relationship with Inflammation
}

\author{
Susana Rovira-Llopis ${ }^{\text {a }} \quad$ Irene Escribano-Lopez ${ }^{\text {a }} \quad$ Noelia Diaz-Morales $^{a}$ \\ Francesca lannantuoni ${ }^{a}$ Sandra Lopez-Domenecha ${ }^{a}$ Isabel Andújar ${ }^{a}$ Ana Jover ${ }^{a}$ \\ Jonay Pantoja ${ }^{b}$ Luis M. Pallardo ${ }^{b, c}$ Celia Bañuls ${ }^{a}$ Victor M. Victor ${ }^{a, d, e}$
}

aService of Endocrinology and Nutrition, University Hospital Doctor Peset, Foundation for the Promotion of Health and Biomedical Research in the Valencian Region (FISABIO), Valencia, 'bervice of Nephrology, University Hospital Doctor Peset, Foundation for the Promotion of Health and Biomedical Research in the Valencian Region (FISABIO), Valencia, 'Department of Medicine, University of Valencia, Valencia, ${ }^{d}$ CIBERehd - Department of Pharmacology, University of Valencia, Valencia, eDepartment of Physiology, University of Valencia, Valencia, Spain

\section{Key Words}

Inflammation • Leukocyte-endothelial interaction • miRNAs • Nephropathy • Type 2 diabetes

\begin{abstract}
Background/Aims: There is a lack of reliable biological markers for the early diagnosis of diabetic nephropathy (DN) during type 2 diabetes. In this pilot study we aim to assess whether miR-31 levels are modulated by the presence of DN and whether the expression of this miRNA is related to leukocyte-endothelial interactions and inflammation. Methods: Thirtyone T2D patients were enrolled in this pilot study; 18 with no diabetic complications and 13 with diabetic nephropathy. 24 non-diabetic subjects and 13 T2D patients with retinopathy (absent of other complications) were included to test the specificity of miR-31. Following anthropometric and biochemical evaluation, serum miR-31 levels were assessed by Real TimePCR. Leukocyte-endothelial interactions were evaluated by a parallel flow chamber in vitro model. Serum TNF $\alpha$, IL- 6 and ICAM-1 levels were determined by XMAP-technology in a flow cytometry-based Luminex 200 instrument. Results: Serum miR-31 levels were similar between control and T2D subjects. However, T2D patients with DN displayed reduced levels of miR-31 with respect to patients without complications. This decrease in miR-31 was more pronounced in patients with macroalbuminuria than in those with microalbuminuria and was specific for DN, since patients with retinopathy displayed unaltered miR-31 levels. The presence of DN involved a lower leukocyte rolling velocity and an increased rolling flux and adhesion. miR31 levels were positively correlated with leukocyte rolling velocity and negatively associated to leukocyte adhesion, TNF $\alpha$, IL- 6 and ICAM-1 levels. Conclusion: Serum miR-31 may be
\end{abstract}


a biomarker for DN in T2D patients. The regulation of this miRNA seems to be related to the recruitment of leukocytes to vascular walls induced by pro-inflammatory and adhesion molecules.

(C) 2018 The Author(s)

Published by S. Karger AG, Basel

\section{Introduction}

Type 2 diabetes (T2D) is dramatically increasing worldwide. In 2015, the prevalence of diabetes in adults aged $20-79$ years was estimated to be $8.8 \%$ and predicted to rise to $10.4 \%$ in 2040 [1]. Long-term vascular complications associated with T2D are the consequence of hyperglycaemic damage to blood vessels and pose a risk for patients.

Diabetic nephropathy (DN) is one of the most relevant microvascular complications of T2D and represents the most frequent cause of end-stage renal disease among the T2D population [2]. DN is characterized by increased glomerular hyperperfusion and hyperfiltration, promoting abnormal high albumin excretion in urine - termed albuminuria - together with a decrease in the estimated glomerular filtration rate (eGFR) [3]. The chronic systemic inflammation present in T2D is even more pronounced in patients with $\mathrm{DN}$, since levels of the pro-inflammatory cytokines tumour necrosis factor alpha (TNF $\alpha$ ) and interleukins 1, 6 and 18 (IL-1, IL-6, and IL-18) are markedly increased and act as pathogenic mediators [4]. Adhesion molecules including intercellular adhesion molecule 1 (ICAM-1), vascular cell adhesion protein 1 (VCAM-1) or E-selectin are also implicated in the physiopathology of DN, favouring immune cell infiltration in renal tissues [5]. In this sense, we have previously shown that T2D patients with DN are characterized by oxidative stress, increased inflammation and adhesion molecule levels, together with enhanced interactions between leukocytes and endothelial cells [6].

Despite intensive research in recent years, there is a lack of biological markers for the early detection of DN. MicroRNAs (miRNAs) have been proposed as predictors of several medical conditions, including multiple cancer types or cardiovascular diseases [7-9]. MiRNAs are non-coding RNAs of $\sim 22$ nucleotides that act as post-transcriptional regulators of gene expression and modulate multiple physiological processes. Levels of miRNAs in human serum are stable, reproducible and consistent, which makes them useful and sensitive biomarkers for different conditions [10].

For example, abnormal expression of several miRNAs has been observed in response to a glucose challenge in healthy subjects [11], or in different tissues of T2D subjects [12]. Intriguingly, upregulation of serum miR-31 has been reported in a group of T2D patients with microvascular complications (retinopathy, neuropathy or nephropathy), although the study in question did not reveal the miR-31 expression level in each of the complications under scrutiny [13]. Suarez et al. revealed that miR-31 targets E-selectin, thus regulating the binding of neutrophils to endothelial cells [14]. In patients suffering from coronary artery disease (CAD), serum miR-31 levels are decreased and this downregulation contributes to CAD pathogenesis [15].

In light of all this evidence, we aimed to investigate whether the presence of DN influenced serum levels of miR-31 in T2D patients, revealing the possible value of this miRNA as a biomarker of DN. Furthermore, potential correlations between miR-31 and leukocyteend othelial interactions and pro-inflammatory and adhesion molecule levels were evaluated in our study population. 


\section{Cellular Physiology Cell Physiol Biochem 2018;50:1005-1014 \begin{tabular}{l|l|l} 
and Biochemistry Published online: 23 October 2018 & $\begin{array}{l}\text { (c) } 2018 \text { The Author(s). Published by S. Karger AG, Basel } \\
\text { www.karger.com/cpb }\end{array}$ \\
\hline
\end{tabular} \\ Rovira-Llopis et al.: miR-31 and Diabetic Nephropathy}

\section{Materials and Methods}

\section{Subjects}

Thirty-one T2D patients attending the Endocrinology and Nutrition Service of the University Hospital Doctor Peset (Valencia, Spain) were enrolled in this study. Diagnosis of T2D was made in accordance with the American Diabetes Association's criteria. Patients were subdivided in two groups, one with 18 subjects that were absent of any diabetes-related vascular complications and the other with 13 patients with DN, which was confirmed when the urine albumin/creatinine ratio was $>30 \mathrm{mg} / \mathrm{g}$. Microalbuminuria or macroalbuminuria was considered in patients with albumin/creatinine values of $30-299 \mathrm{mg} / \mathrm{g}$ or $\geq 300$ $\mathrm{mg} / \mathrm{g}$, respectively on at least two occasions. In addition, a group of thirteen T2D patients with retinopathy was included to test the specificity of miR-31. Retinopathy was confirmed by ophthalmologists by means of funduscopic examination. Each patient group was composed exclusively of subjects with the specific complication; in this way, DN patients did not have retinopathy, and patients in the retinopathy group were normoalbuminuric. Patients were excluded if they fulfilled any of the following criteria: autoimmune, infectious, haematological, malignant, organic or inflammatory diseases; morbid obesity (body mass index $\left[\mathrm{BMI} \geq 40 \mathrm{~kg} / \mathrm{m}^{2}\right]$ ); history of cardiovascular disease (including ischemic heart disease, peripheral vascular disease, stroke, and chronic disease related to cardiovascular risk); fever; intense physical exercise and diabetic neuropathy. Twenty-four age and sex-matched non-diabetic subjects (which did not fulfill any of the American Diabetes Association's criteria for the diagnosis of T2D) were included to assess potential differences in serum miR-31 levels with respect to T2D patients. These subjects were staff members and staff relatives at the Endocrinology Outpatient's Clinic of Valencia's University Hospital Doctor Peset.

The study was conducted according to the Helsinki Declaration and approval by the Ethics Committee of the University Hospital Doctor Peset was obtained. All participants provided their informed written consent as required by said institutions.

\section{Anthropometric and biochemical determinations}

Following overnight fasting, venous blood was collected from the antecubital vein and subjects' body weight $(\mathrm{kg})$, height $(\mathrm{m})$, BMI $\left(\mathrm{kg} / \mathrm{m}^{2}\right)$, waist circumference $(\mathrm{cm})$, and systolic and diastolic blood pressure (SBP and DBP, $\mathrm{mmHg}$ ) were recorded. Blood was centrifuged (1500g, $10 \mathrm{~min}, 4^{\circ} \mathrm{C}$ ) and levels of glucose, total cholesterol and triglycerides in serum were evaluated by an enzymatic method. Glycated haemoglobin (HbA1c) levels were evaluated by means of an automatic glycohemoglobin analyzer (ARKRAY Europe). Levels of urinary albumin were determined in urine samples obtained in the morning by means of immunoturbidimetry.

\section{miRNA isolation and miR-31 determination}

Blood samples were collected in serum-separator tubes and centrifuged at $1500 \mathrm{~g}$ for $10 \mathrm{~min}$ at $4^{\circ} \mathrm{C}$. The supernatant (serum) was stored at $-80^{\circ} \mathrm{C}$ until analysis. Serum circulating miRNAs were isolated using the miRNeasy Serum/Plasma Kit (Qiagen) and cel-miR-39 was used as the spike-in control. RNA was converted into cDNA using the TaqMan Advanced miRNA cDNA Synthesis Kit (Thermo Fisher Scientific) following the manufacturer's instructions. The expression levels of miR-31 and the internal control celmiR-39 were assessed by qPCR with specific hydrolysis probes (Thermo Fisher Scientific) in a 7500 Fast Real Time PCR System (Applied Biosystems) and the relative gene expression for miR-31 was obtained using the $2^{-\triangle \Delta C T}$ method with ExpressionSuite software (Applied Biosystems).

\section{Polymorphonuclear leukocyte isolation}

Heparinized blood samples were incubated with dextran (3\% in saline) for $45 \mathrm{~min}$. The supernatant was collected and released over Ficoll-Hypaque (GE Healthcare), and the samples were then centrifuged (650g, $25 \mathrm{~min}$ ) to obtain polymorphonuclear leukocytes (PMNs) as a cell pellet. Lysis buffer was added to the cell pellet, incubated for $5 \mathrm{~min}$ at room temperature and centrifuged $(240 \mathrm{~g}, 5 \mathrm{~min})$ to remove the remaining lysed erythrocytes. Cells were then resuspended in Hanks' balanced salt solution (Sigma Aldrich) and counted with a Scepter 2.0 cell counter (Merck Millipore). 


\section{Cellular Physiology Cell Physiol Biochem 2018;50:1005-1014 \begin{tabular}{l|l|l} 
and Biochemistry Published online: 23 October 2018 & $\begin{array}{l}\text { (c) } 2018 \text { The Author(s). Published by S. Karger AG, Basel } \\
\text { www.karger.com/cpb }\end{array}$ \\
\hline
\end{tabular}

\section{Leukocyte-endothelial interaction assay}

We employed an in vitro model of leukocyte-endothelial interactions in which isolated PMNs of each subject were perfused at a flow rate of $0.36 \mathrm{ml} / \mathrm{min}$ over a human umbilical vein endothelial cell (HUVEC) monolayer seeded on coverslips in the bottom plate of a flow chamber. HUVEC were obtained from fresh umbilical cords of healthy donors that gave their informed consent.

During the experiment, a $5 \times 25 \mathrm{~mm}$ portion of the endothelial monolayer was exposed and recorded during a 5-min period with a video camera (Sony Exware HAD) connected to an inverted microscope (Nikon Eclipse TE 2000-S). These 5-min videos were analysed to evaluate the following parameters: leukocyte rolling velocity, estimated as the time required by 20 consecutive leukocytes to travel along $100 \mu \mathrm{m}$ of the exposed field; rolling flux, which is the number of leukocytes rolling over a $100 \mu \mathrm{m}^{2}$ surface of HUVEC cells over $1 \mathrm{~min}$; and leukocyte adhesion, defined as the number of leukocytes that bind to the endothelial monolayer for at least 30s. The positive controls platelet-activating factor $(1 \mu \mathrm{M}, 1 \mathrm{~h})$ and TNF $\alpha(10 \mathrm{ng} / \mathrm{ml}$, 4h) were employed for leukocytes and HUVEC, respectively.

\section{Levels of inflammatory cytokines and adhesion molecules}

Serum TNF $\alpha$, IL-6 and ICAM-1 levels were assessed using X-MAP technology in a Luminex 100 flow analyser following the manufacturer's instructions (Merck Millipore).

\section{Statistical analysis}

Statistical assessments were performed with SPSS Statistics 15.0 (SPSS Inc.). Non-nephropathy and nephropathy groups were compared using the parametric Student's t-test or the non-parametric MannWhitney's U-test, depending on the normality of data. To compare more than two groups we employed the Kruskal-Wallis test and Dunn's multiple comparison post hoc test. Spearman's rank correlation coefficients were used to study the associations between miR-31 and the inflammation/adhesion variables. Data in bar graphs are presented as means \pm standard error of the mean. Statistical significance was set at $\mathrm{p}<0.05$.

\section{Results}

Anthropometric and biochemical parameters

The characteristics of the study population are shown in Table 1 . T2D patients were divided into two groups according to the presence of DN. Patients with DN did not differ from those without nephropathy for duration of diabetes (11.9 \pm 9.7 vs. $9.0 \pm 4.6$, respectively) or any of the anthropometric parameters studied; namely weight, BMI, waist circumference, SBP and DBP ( $p>0.05)$. Regarding biochemical determinations, no differences were observed for fasting glucose, $\mathrm{HbA1c}$, total cholesterol and triglycerides between T2D patients with DN and those without complications. As
Table 1. Anthropometric, biochemical and clinical characteristics of type 2 diabetic patients separated according to the absence/presence of diabetic nephropathy. Data are expressed as mean \pm standard deviation for parametric variables and as median $\left(25^{\text {th }}\right.$ percentil $-75^{\text {th }}$ percentil) for non-parametric variables. Comparisons were made using the Student's $t$ test for parametric variables and the Mann Whitney U test for non-parametric variables

\begin{tabular}{lccc}
\hline Parameter & Type 2 diabetes without complications & Type 2 diabetes with nephropathy & P value \\
\hline N (\% male) & $18(66.7)$ & $13(76.9)$ & $\mathrm{ns}$ \\
Age (years) & $56.9 \pm 8.7$ & $61.2 \pm 8.4$ & $\mathrm{~ns}$ \\
Duration of the disease (years) & $9.0 \pm 4.6$ & $11.9 \pm 9.7$ & $\mathrm{~ns}$ \\
Weight (kg) & $80.0 \pm 21.1$ & $82.8 \pm 7.4$ & $\mathrm{~ns}$ \\
BMI (kg/m²) & $28.2 \pm 4.9$ & $29.5 \pm 3.8$ & $\mathrm{~ns}$ \\
Waist circumference (cm) & $99.2 \pm 16.2$ & $106.5 \pm 7.7$ & $\mathrm{~ns}$ \\
SBP (mmHg) & $132.7 \pm 13.3$ & $140.4 \pm 19.8$ & $\mathrm{~ns}$ \\
DBP (mmHg) & $77.1 \pm 10.4$ & $78.4 \pm 13.0$ & $\mathrm{~ns}$ \\
Glucose (mg/dl) & $146.1 \pm 38.9$ & $169.5 \pm 69.6$ & $\mathrm{~ns}$ \\
HbA1c (\%) (mmol/mol) & $7.28 \pm 1.47(55.5 \pm 16.2)$ & $7.62 \pm 2.15(59.6 \pm 23.6)$ & $\mathrm{ns}$ \\
Total cholesterol (mg/dl) & $157.1 \pm 28.7$ & $167.4 \pm 51.5$ & $\mathrm{~ns}$ \\
Triglycerides (mg/dl) & $85.0(68.0-205.3)$ & $159.0(126.5-235.5)$ & $\mathrm{ns}$ \\
Microalbuminuria (mg/l) & $7.0(5.0-16.8)$ & $58.5(27.8-143.3)$ & $<0.01$ \\
Albumin/creatinine (mg/g) & $9.5(5.3-19.1)$ & $54.0(43.4-181.4)$ & $<0.01$ \\
eGFR (ml/min/1.73 m²) & $93.8 \pm 11.0$ & $79.7 \pm 21.5$ & $<0.05$ \\
\hline
\end{tabular}




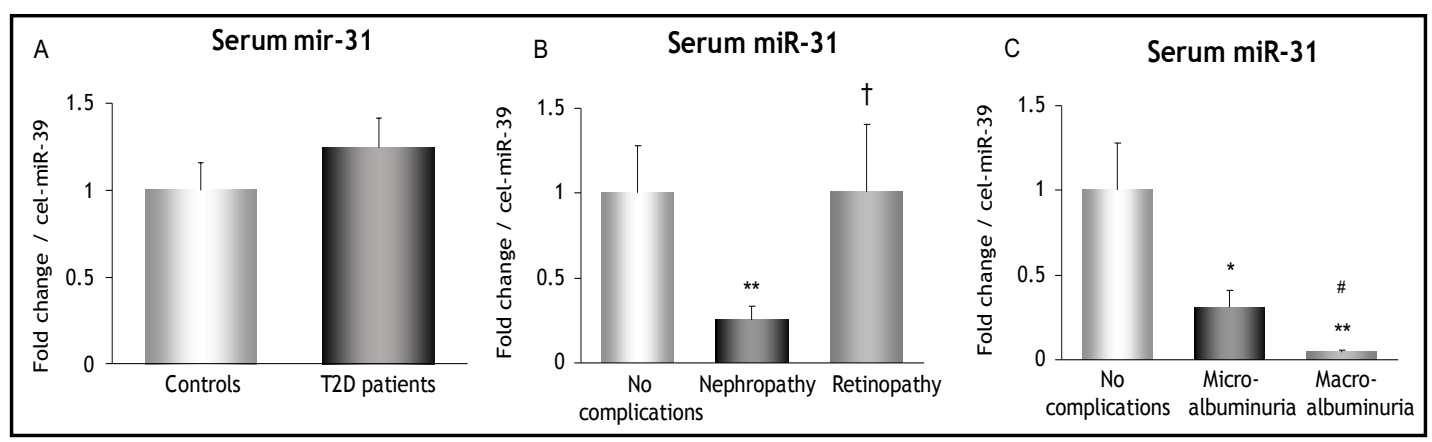

Fig. 1. Levels of miR-31 in the serum of control subjects and T2D patients. The values of the relative gene expression for miR-31 were normalized to cel-miR-39 and calculated using the $2^{-\Delta \Delta C T}$ method. (A) Controls vs. T2D patients (B) T2D patients without any complication, with nephropathy or with retinopathy (C) T2D patients without any complication and with nephropathy, categorized in two groups according to the severity of the disease (microalbuminuria or macroalbuminuria). ${ }^{*} \mathrm{p}<0.05$ and ${ }^{* *} \mathrm{p}<0.01$, compared to the no complications group; $\dagger \mathrm{p}<0.05$ when compared Nephropathy vs. Retinopathy groups; \# $\mathrm{p}<0.05$ when compared Micro- vs Macroalbuminuria groups.

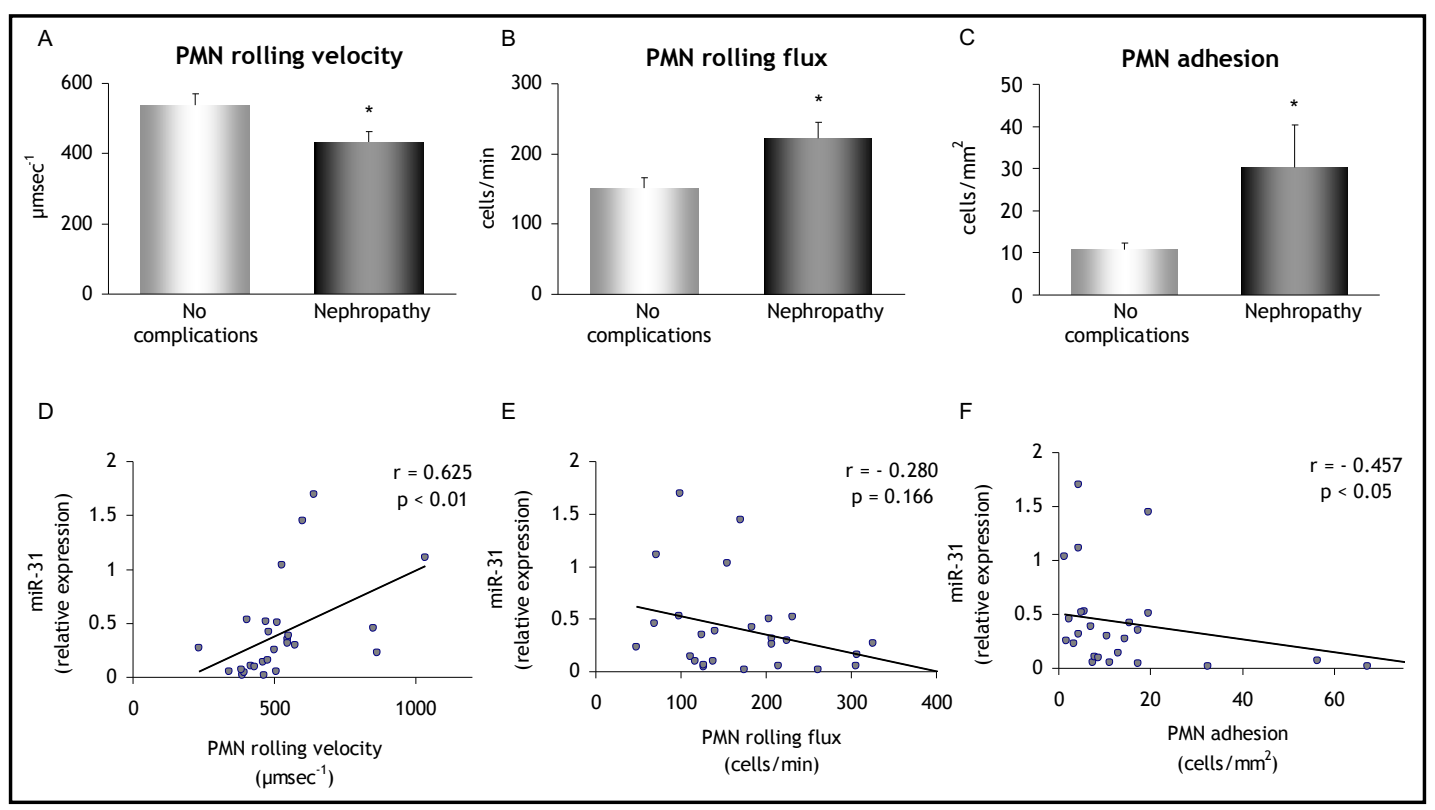

Fig. 2. Comparison of leukocyte-endothelial interactions in $T 2 D$ patients depending on the presence of nephropathy and their relation to miR-31 levels. (A) Leukocyte rolling velocity, (B) Leukocyte rolling flux, (C) Leukocyte adhesion, (D) Correlation between miR-31 levels and leukocyte rolling velocity, (E) Correlation between miR-31 levels and leukocyte rolling flux, (F) Correlation between mir-31 levels and leukocyte adhesion. ${ }^{*} \mathrm{p}<0.05$.

expected, patients with nephropathy displayed increased microalbuminuria and albumin/ creatinine values $(\mathrm{p}<0.01)$, and reduced eGFR $(\mathrm{p}<0.05)$. No statistical significance was detected between the different patient groups with respect to the treatments used. Antihypertensive medication was taken by $32 \%$ of patients, statins by $67 \%$, fibrates by $15 \%$, metformin by $69 \%$, DPP- 4 inhibitors by $42 \%$, insulin by $46 \%$, glucagon-like peptide- 1 receptor agonists by $11.5 \%$ and SGLT2 inhibitors by $11.5 \%$. 


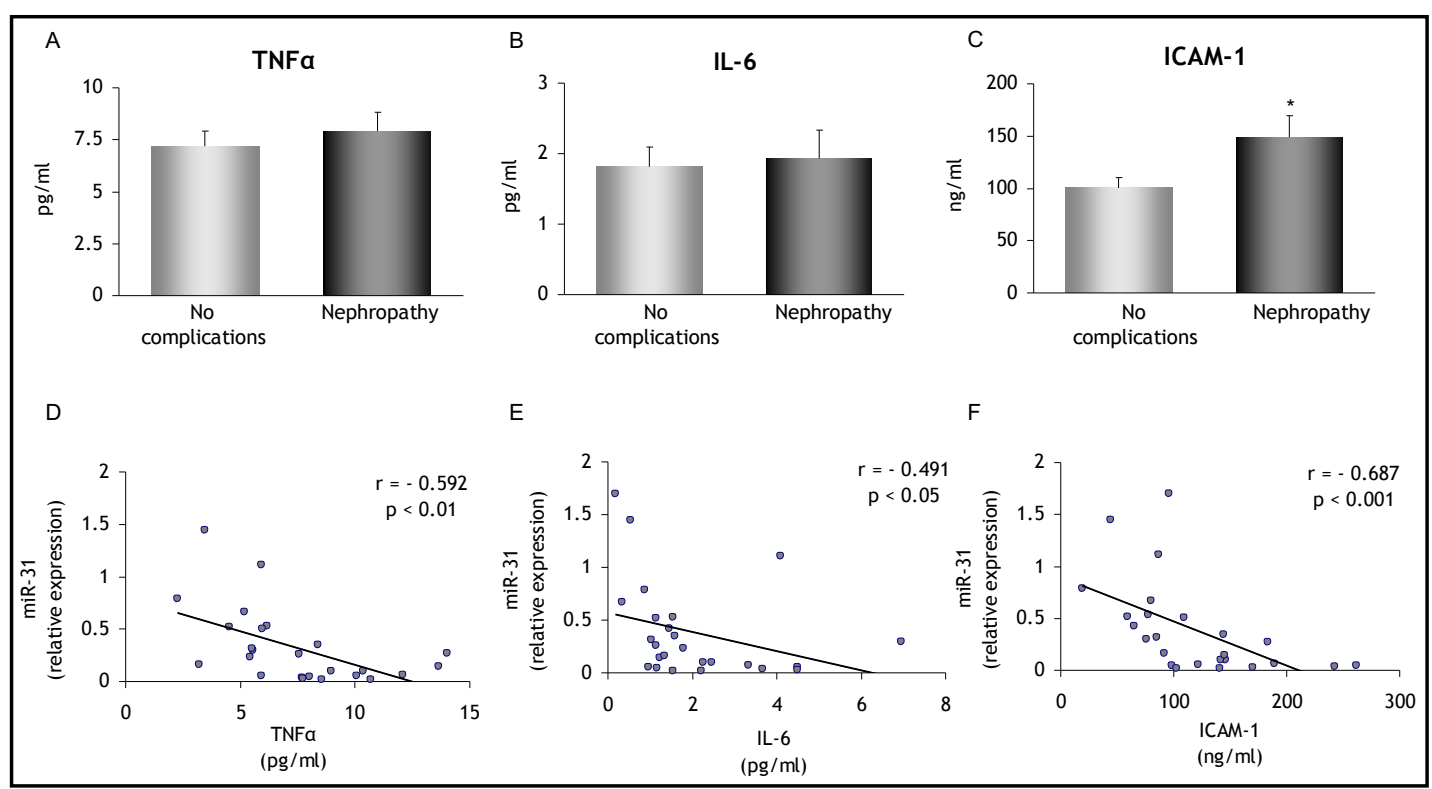

Fig. 3. Cytokines and adhesion molecules in T2D patients without any complications or with nephropathy and association of miR-31 levels with these molecules. (A) TNF $\alpha$ levels in patients without complications vs. nephropathy patients, (B) IL-6 levels, (C) ICAM-1 levels, (D) Correlation between miR-31 levels and TNF $\alpha$, (E) Correlation between miR-31 levels and IL-6, (F) Correlation between miR-31 levels and ICAM-1. *p<0.05.

\section{Serum miR-31 levels}

Levels of mir-31 in T2D patients $(n=31)$ were similar to those of age and sex-matched healthy subjects $(n=24)$ (Fig. 1A, $p=0.30)$. Thus, we focused on the regulation of the expression levels of this miRNA within the T2D population. As shown in Fig. 1B, miR-31 levels were found to be reduced in the sera of T2D patients with DN ( $p<0.001$ with respect to the group without complications). To test whether the decrease in miR-31 was specific to patients with DN and unrelated to microvascular complications in general, we included a group of patients with diabetic retinopathy (without DN). These patients $(n=13 ; 2$ of which had proliferative retinopathy) had an age of $61.7 \pm 6.5$ years, with $15 \pm 5.5$ years duration of diabetes, a BMI of $32.2 \pm 5.0 \mathrm{~kg} / \mathrm{m}^{2}$ and $\mathrm{HbA} 1 \mathrm{c}$ of $7.83 \pm 1.61 \%$, with no statistical differences in these parameters with respect to the other two groups. We did not observe changes in the levels of miR-31 in this retinopathy group with respect to T2D patients without complications, whereas levels of miR-31 in the retinopathy group were significantly increased with respect to the nephropathy group (Fig. 1B). In addition, when patients with DN were subdivided according to the severity of the disease, we observed a more pronounced decrease in the levels of miR-31 in those with macroalbuminuria (Fig. 1C, p $<0.01$ with respect to patients without complications; $\mathrm{p}<0.05$ with respect to patients with microalbuminuria). A trend for a negative association between miR-31 and albumin/creatinine ratio was detected $(\mathrm{r}=$ $-0.337 ; \mathrm{p}=0.069$ ).

\section{Relationship between miR-31 levels and leukocyte-endothelial interactions}

DN was accompanied by enhanced interactions between leukocytes and endothelial cells, as suggested by our in vitro model. PMN rolling velocity (Fig. $2 \mathrm{~A}, \mathrm{p}<0.05$ ) was reduced and PMN rolling flux and adhesion augmented in patients with nephropathy with respect to those without nephropathy (Fig. 2B-C, p $<0.05$ in both cases). These leukocyte interactions were related to the amount of miR-31 in serum, as we observed a positive correlation between miR-31 and PMN rolling velocity (Fig. 2D, $r=0.625 ; \mathrm{p}<0.01$ ) and a negative correlation between miR-31 and PMN adhesion (Fig. 2F, $r=-0.457 ; \mathrm{p}<0.05$ ). We also found a trend toward an increased rolling flux associated with a decrease in miR-31, although the association did not reach statistical significance (Fig. $2 \mathrm{E}, \mathrm{r}=-0.280 ; \mathrm{p}=0.166$ ). 


\section{Cellular Physiology Cell Physiol Biochem 2018;50:1005-1014 \begin{tabular}{ll|l} 
DOI: 10.1159/000494482 & $\begin{array}{l}\text { O } 2018 \text { The Author(s). Published by S. Karger AG, Basel } \\
\text { www.karger.com/cpb }\end{array}$
\end{tabular}

\section{Association of serum miR-31 with inflammatory and adhesion molecule levels}

We did not find significant differences in pro-inflammatory cytokines between nephropathy and non-nephropathy groups (Fig. 3A-B). However, ICAM-1 levels were increased in patients with DN with respect to those without complications (Fig. 3C). Interestingly, miR-31 was associated with the inflammatory status of the patients, since we found negative correlations between miR-31 and TNF $\alpha(\mathrm{r}=-0.592 ; \mathrm{p}<0.01)$, IL-6 $(\mathrm{r}=-0.491$; $\mathrm{p}<0.05$ ) and ICAM-1 levels ( $\mathrm{r}=-0.687 ; \mathrm{p}<0.001$ ) (Fig. 3D-F).

\section{Discussion}

The results of the present study reveal a novel association between reduced circulating miR-31 levels and the progression of DN (from micro- to macroalbuminuria) in T2D patients with nephropathy and a mean duration of the disease of $11.9 \pm 9.7$ years. In addition, miR-31 levels were negatively associated with the albumin-to-creatinine ratio. We also witnessed an association between the drop in miR-31 levels, reduced leukocyte rolling velocity and enhanced leukocyte adhesion to the endothelium. Negative associations were found between miR-31, the pro-inflammatory cytokines TNF $\alpha$ and IL- 6 and the adhesion molecule ICAM-1, suggesting a worsening of inflammation as levels of miR-31 decrease. Our findings support a potential role of miR-31 in the regulation of inflammation-dependent leukocyte-endothelial cell interactions.

DN occurs progressively during T2D in a substantial proportion of patients, specially in those with poor glycaemic control, long duration of diabetes, hypertension or advanced age [16]. Although a lot of research has been done on the search of novel treatments for established DN [17-19], the development of tools for the early detection and prognosis of DN is needed in order to identify patients at risk and carry out interventional strategies to prevent the onset of DN. Several miRNAs have been related to the pathological mechanisms of DN [20]; for example, miR-192, which is specifically expressed in the kidney, is downregulated in patients with established DN, and has been related to increased fibrosis and reduced eGFR [21]. Similarly, upregulation of miR-21 in the kidney as a consequence of T2D-associated hyperglycaemia induces renal cell hypertrophy and fibrogenesis [22]. These miRNAs are reported to serve as biomarkers of the disease, since their abnormal levels in serum may reflect the underlying progression of renal impairment [23]. However, their serum expression levels seem to be altered at advanced stages of DN, as they are not obvious in patients with microalbuminuria. For this reason, a reliable marker able to determine the onset of DN at the early stages would be useful for the prevention of this microvascular complication.

The results of the present pilot study reveal that serum miR-31 levels are reduced specifically in patients with DN, and not in patients with retinopathy, and that the decrease occurs as DN progresses. Moreover, it is more pronounced in T2D patients with macroalbuminuria, but is also significant in patients with microalbuminuria, suggesting that circulating miR-31 levels reflect the stage of the disease, though further studies are needed to confirm this association. Follow up studies to monitor miR-31 in the circulation and perform tissue-specific assessment of this miRNA in T2D patients may shed light on the potential value of miR-31 as a biomarker of DN.

Chronic low-grade inflammation is a hallmark of T2D and contributes to the pathogenesis and progression of DN $[24,25]$. Inflammatory signalling by NF- $\kappa \mathrm{B}$ in the kidney during DN prompts the release of cytokines, chemokines and adhesion molecules that mediate the migration and infiltration of immune cells into the kidney tissues [26]. Similarly, leukocytes migrate to the vascular walls in inflammatory situations, a multistep process regulated by cytokines released by leukocytes and adhesion molecules in endothelial cells [27]. We have previously demonstrated that the different steps involved in leukocyte recruitment - namely leukocyte rolling and adhesion - are enhanced in T2D patients and even more pronounced in patients with DN [6]. In the present study, we confirm these observations and also demonstrate a positive correlation between miR-31 and PMN rolling velocity as 
well as a negative correlation between miR-31 and PMN adhesion, suggesting that the regulation of leukocyte-endothelial cell interactions is associated with the regulation of this miRNA. Interestingly, we have also observed inverse correlations between serum miR-31 levels and the pro-inflammatory cytokines TNF $\alpha$ and IL-6. The adhesion molecule ICAM-1 was also inversely associated with miR-31 levels. Likewise, other authors have reported a relationship between miR-31 and inflammatory/adhesion molecules $[28,14]$. For example, Yan et al. described that IL- 6 induced expression of miR-31 mediated by NF- $\kappa$ B signalling in keratinocytes [28]. Another study, by, Suarez et al., identified miR-31 as a negative feedback regulator of TNF $\alpha$-induced E-selectin expression. The authors also described how overexpression of miR-31 reduced neutrophil binding to endothelial cells, which is in line with our present results [14]. Future studies may reveal the specific mechanism by which miR-31 regulates inflammatory and adhesion molecule expression and whether molecules besides those considered in our study are modulated by miR-31.

These findings support a protective role for miR-31 in inflammation-derived leukocyteendothelial interplay, which may explain the reduction in miR-31 levels observed in our cohort of patients with nephropathy, in which leukocyte-endothelial contact was exacerbated. miR31 has previously been reported to target several integrin subunits to regulate key aspects of cancer cell invasion and metastasis [29] and, as mentioned above, to target E-selectin in the context of inflammation [14]. In this context, we hypothesize that the targets of miR31 could be the main types of adhesion molecules, such as integrins or selectins, which would explain the negative correlations between the levels of circulating miR-31 and the interactions between leukocytes and endothelium.

A limitation of the present study is that this is a pilot study with a limited number of patients. Nevertheless, our results are strengthened by the observed specificity of miR-31 reduction to DN, since patients with DN were free of any other complication, and retinopathy patients (also absent of other complications) did not show this reduction.

\section{Conclusion}

In summary, our findings suggest that serum levels of miR-31 are related to the development of DN, since their decline occurs in parallel to the disease's progression, thus endorsing a potential role for miR-31 as a sensitive prognostic biomarker of DN. miR-31 also seems to be associated with inflammation and increased interaction between leukocytes and endothelial cells, both common pathological features of diabetic vascular complications [6, 30]. Further research is needed to reveal the specific role of this miRNA in the context of T2D in general and specifically in DN, and to confirm its potential as a biological marker of DN.

\section{Acknowledgements}

Authors thank B. Normanly (University of Valencia) for his editorial assistance, and Rosa Falcón and Carmen Ramirez (FISABIO) for their technical assistance.

This study was financed by grants PI16/01083 and CIBERehd CB06/04/0071, from the Carlos III Health Institute; UGP-15-220 from FISABIO; by the European Regional Development Fund (ERDF "A way to build Europe") and by an unrestricted grant from Menarini S.A. S.R-L. is recipient of a Juan de la Cierva-Formación contract from the Spanish Ministry of Economy and Competitiveness (FJCI-2015-25040). I.E.-L. is recipient of a predoctoral contract from FISABIO (UGP-15-144). N.D.-M. and S.L.-D. are recipients of PFIS contracts from Carlos III Health Institute (FI14/00125 and FI14/00350, respectively). F.I is recipient of contract from the Department of Education of the Valencian Regional Government 


\section{Cellular Physiology Cell Physiol Biochem 2018;50:1005-1014 \begin{tabular}{l|l} 
DOI: 10.1159/000494482 & O) 2018 The Author(s). Published by S. Karger AG, Basel \\
www.karger.com/cpb
\end{tabular} \\ Rovira-Llopis et al.: miR-31 and Diabetic Nephropathy}

(GRISOLIAP/2016/015). C.B. and I.A. are recipient of a Sara Borrell contract from Carlos III Health Institute (CD14/00043 and CD15/00236, respectively). V.M.V. is recipient of a contract from the Ministry of Health of the Valencian Regional Government and Carlos III Health Institute (CES10/030).

\section{Disclosure Statement}

The authors declare no conflicts of interest.

\section{References}

1 Ogurtsova K, da Rocha Fernandes JD, Huang Y, Linnenkamp U, Guariguata L, Cho NH, Cavan D, Shaw JE, Makaroff LE: IDF Diabetes Atlas: Global estimates for the prevalence of diabetes for 2015 and 2040. Diabetes Res Clin Pract 2017;128:40-50.

-2 Bell S, Fletcher EH, Brady I, Looker HC, Levin D, Joss N, Traynor JP, Metcalfe W, Conway B, Livingstone S, Leese G, Philip S, Wild S, Albesma N, Sattar N, Lindsay RS, McKnight J, Pearson D, Colhoun HM: End-stage renal disease and survival in people with diabetes: a national database linkage study. Scottish Diabetes Research Network and Scottish Renal Registry. QJM 2015;108:127-134.

-3 Rossing K, Christensen PK, Hovind P, Tarnow L, Rossing P, Parving HH: Progression of nephropathy in type 2 diabetic patients. Kidney Int 2004;66:1596-1605.

4 Navarro-González JF, Mora-Fernández C: The role of inflammatory cytokines in diabetic nephropathy. J Am Soc Nephrol 2008;19:433-442.

-5 Navarro-González JF, Mora-Fernández C, Muros de Fuentes M, García-Pérez J: Inflammatory molecules and pathways in the pathogenesis of diabetic nephropathy. Nat Rev Nephrol 2011;7:327-340.

-6 Rovira-Llopis S, Rocha M, Falcon R, de Pablo C, Alvarez A, Jover A, Hernandez-Mijares A, Victor VM: Is myeloperoxidase a key component in the ROS-induced vascular damage related to nephropathy in type 2 diabetes? Antioxid Redox Signal 2013;19:1452-1458.

7 Wang J, Chen J, Sen S: MicroRNA as Biomarkers and Diagnostics. J Cell Physiol 2016;231:25-30.

$>8$ Dong Q, Li C, Che X, Qu J, Fan Y, Li X, Li Y, Wang Q, Liu Y, Yang X, Qu X: MicroRNA-891b is an independent prognostic factor of pancreatic cancer by targeting Cbl-b to suppress the growth of pancreatic cancer cells. Oncotarget 2016;7:82338-82353.

-9 Greco S, Fasanaro P, Castelvecchio S, D’Alessandra Y, Arcelli D, Di Donato M, Malavazos A, Capogrossi MC, Menicanti L, Martelli F: MicroRNA dysregulation in diabetic ischemic heart failure patients. Diabetes 2012;61:1633-1641.

10 Chen X, Ba Y, Ma L, Cai X, Yin Y, Wang K, Guo J, Zhang Y, Chen J, Guo X, Li Q, Li X, Wang W, Zhang Y, Wang J, Jiang X, Xiang Y, Xu C, Zheng P, Zhang J et al.: Characterization of microRNAs in serum: a novel class of biomarkers for diagnosis of cancer and other diseases. Cell Res 2008;18:997-1006.

11 Yan X, Wang Z, Westberg-Rasmussen S, Tarbier M, Rathjen T, Tattikota SG, Peck BCE, Kanke M, Oxvig C, Frystyk J, Starup-Linde J, Sethupathy P, Friedländer MR, Gregersen S, Poy MN: Differential impact of glucose administered intravenously and orally on circulating miR-375 levels in human subjects. J Clin Endocrinol Metab 2017;102:3749-3755.

12 Pandey AK, Agarwal P, Kaur K, Datta M: MicroRNAs in diabetes: tiny players in big disease. Cell Physiol Biochem 2009;23:221-232.

13 Sebastiani G, Nigi L, Spagnuolo I, Morganti E, Fondelli C, Dotta F: MicroRNA profiling in sera of patients with type 2 diabetes mellitus reveals an upregulation of miR-31 expression in subjects with microvascular complications. J Biomedical Science and Engineering 2013;6:58-64.

14 Suárez Y, Wang C, Manes TD, Pober JS: Cutting edge: TNF-induced microRNAs regulate TNF-induced expression of E-selectin and intercellular adhesion molecule-1 on human endothelial cells: feedback control of inflammation. J Immunol 2010;184:21-25. 


\section{Cellular Physiology Cell Physiol Biochem 2018:50:1005-1014 \begin{tabular}{l|l} 
DOI: 10.1159/000494482 & O 2018 The Author(s). Published by S. Karger AG, Basel \\
www.karger.com/cpb
\end{tabular} \\ Rovira-Llopis et al.: miR-31 and Diabetic Nephropathy}

15 Wang HW, Huang TS, Lo HH, Huang PH, Lin CC, Chang SJ, Liao KH, Tsai CH, Chan CH, Tsai CF, Cheng YC, Chiu YL, Tsai TN, Cheng CC, Cheng SM: Deficiency of the microRNA-31-microRNA-720 pathway in the plasma and endothelial progenitor cells from patients with coronary artery disease. Arterioscler Thromb Vasc Biol 2014;34:857-869.

16 Satirapoj B, Adler SG: Comprehensive approach to diabetic nephropathy. Kidney Res Clin Pract 2014;33:121-131.

17 Hou B, Qiang G, Zhao Y, Yang X, Chen X, Yan Y, Wang X, Liu C, Zhang L, Du G: Salvianolic acid A protects against diabetic nephropathy through ameliorating glomerular endothelial dysfunction via inhibiting AGERAGE signaling. Cell Physiol Biochem 2017;44:2378-2394.

18 Yang S, Zhang J, Wang S, Shi J, Zhao X: Knockdown of angiopoietin-like protein 2 ameliorates diabetic nephropathy by inhibiting TLR4. Cell Physiol Biochem 2017;43:685-696.

19 Han H, Cao A, Wang L, Guo H, Zang Y, Li Z, Zhang X, Peng W: Huangqi decoction ameliorates streptozotocininduced rat diabetic nephropathy through antioxidant and regulation of the TGF- $\beta /$ MAPK/PPAR- $\gamma$ signaling. Cell Physiol Biochem 2017;42:1934-1944.

20 Rudnicki M, Beckers A, Neuwirt H, Vandesompele J: RNA expression signatures and posttranscriptional regulation in diabetic nephropathy. Nephrol Dial Transplant 2015;30 Suppl 4:iv35-42.

21 Krupa A, Jenkins R, Luo DD, Lewis A, Phillips A, Fraser D: Loss of MicroRNA-192 promotes fibrogenesis in diabetic nephropathy. J Am Soc Nephrol 2010;21:438-447.

22 Dey N, Das F, Mariappan MM, Mandal CC, Ghosh-Choudhury N, Kasinath BS, Choudhury GG: MicroRNA-21 orchestrates high glucose-induced signals to TOR complex 1, resulting in renal cell pathology in diabetes. J Biol Chem 2011;286:25586-25603.

23 Chien HY, Chen CY, Chiu YH, Lin YC, Li WC: Differential microRNA Profiles Predict Diabetic Nephropathy Progression in Taiwan. Int J Med Sci 2016;13:457-465.

-24 Gilbert RE, Cooper ME: The tubulointerstitium in progressive diabetic kidney disease: more than an aftermath of glomerular injury? Kidney Int 1999;56:1627-1637.

25 Krolewski AS: Progressive renal decline: the new paradigm of diabetic nephropathy in type 1 diabetes. Diabetes Care 2015;38:954-962.

26 Wada J, Makino H: Inflammation and the pathogenesis of diabetic nephropathy. Clin Sci (Lond) 2013;124:139-152.

27 Schnoor M: Endothelial actin-binding proteins and actin dynamics in leukocyte transendothelial migration. J Immunol 2015;194:3535-3541.

28 Yan S, Xu Z, Lou F, Zhang L, Ke F, Bai J, Liu Z, Liu J, Wang H, Zhu H, Sun Y, Cai W, Gao Y, Su B, Li Q Yang X, Yu J, Lai Y, Yu XZ, Zheng Y et al.: NF- $\kappa B$-induced microRNA-31 promotes epidermal hyperplasia by repressing protein phosphatase 6 in psoriasis. Nat Commun 2015;6:7652.

29 Augoff K, Das M, Bialkowska K, McCue B, Plow EF, Sossey-Alaoui K: miR-31 is a broad regulator of $\beta 1$ integrin expression and function in cancer cells. Mol Cancer Res 2011;9:1500-1508.

-30 Hernandez-Mijares A, Rocha M, Rovira-Llopis S, Bañuls C, Bellod L, de Pablo C, Alvarez A, RoldanTorres I, Sola-Izquierdo E, Victor VM: Human leukocyte/endothelial cell interactions and mitochondrial dysfunction in type 2 diabetic patients and their association with silent myocardial ischemia. Diabetes Care 2013;36:1695-1702. 